\title{
The state of smokeless tobacco cessation in a context lacking cessation services: Evidence from Ethiopia
}

\author{
Mamusha A. Hussen ${ }^{1}$, Edao S. Etu²
}

\begin{abstract}
INTRODUCTION Cessation attempts for smokeless tobacco (SLT) have been studied in the countries that provide comprehensive cessation services, but there is no evidence about SLT cessation in Ethiopia, where there are no comprehensive tobacco cessation services. The objective of this study was to determine cessation attempts and related factors among daily SLT users.

METHODS We analyzed the data obtained from a cross-sectional survey of SLT users in Borena zone, Ethiopia, focusing on a subset of 600 daily SLT users. Participants were adult SLT users aged $\geq 18$ years. The dependent variable was SLT cessation attempt. Multivariable logistic regression was performed to identify association between cessation attempts and explanatory variables. Analyses were performed using SPSS version 20.

RESULTS Overall, $18.5 \%$ reported having tried to quit SLT in the past 12 months. In multivariable analyses, SLT cessation attempts were significantly associated with being male (AOR=1.96, 95\% CI: 1.13-3.40), current dual-product user $(\mathrm{AOR}=2.11,95 \% \mathrm{CI}: 1.31-3.38)$, being advised by a health professional $(\mathrm{AOR}=1.82,95 \% \mathrm{CI}: 1.13-2.92)$, current knowledge (AOR=1.20, 95\% CI: 1.00 $1.44)$, and risk perception ( $\mathrm{AOR}=1.06,95 \% \mathrm{CI}: 1.02-1.10)$.

CONCLUSIONS A low cessation attempt rate among daily SLT users calls for comprehensive cessation intervention. More attention to factors such as knowledge of the health consequences of SLT use, risk perception and health workers advice will be required to encourage cessation attempts.
\end{abstract}

ABBREVIATIONS AOR: adjusted odds ratio, DALY: disability adjusted life year, FCTC: Framework Convention on Tobacco Control, SLT: smokeless tobacco, WHO: World Health Organization.

\author{
AFFILIATION \\ 1 Department of Health, \\ Behaviour and Society, \\ Institute of Health, Jimma \\ University, Jimma, Ethiopia \\ 2 Department of Public \\ Health, School of Health \\ Science, Goba Referral \\ Hospital, Madda Walabu \\ University, Goba, Ethiopia \\ CORRESPONDENCE TO \\ Mamusha A. Hussen. \\ Department of Health, \\ Behaviour and Society, \\ Institute of Health, Jimma \\ University, P. 0. Box 378, \\ Jimma, Ethiopia. \\ E-mail: afiigaa@yahoo.com \\ ORCID ID: https://orcid. \\ org/0000-0002-9370-9400
}

KEYWORDS

smokeless tobacco, cessation, Borena zone

Received: 19 June 2019 Revised: 15 September 2019 Accepted: 28 September 2019

\section{INTRODUCTION}

There has been substantial progress in reducing tobacco use globally, however, progress has not been uniform across all countries. Low- and middle-income countries in Africa and in other regions continue to have higher death rates attributable to tobacco use ${ }^{1}$. A review on the status of tobacco production and trade in Africa has shown that the area under tobacco cultivation and the importation of tobacco leaf have increased compared to the other parts of the world ${ }^{2}$.

Smokeless tobacco (SLT) products are a noncombustible form of tobacco consumed widely in the continent ${ }^{3}$. The absence of strong tobacco prevention and control policies, coupled with current efforts to expand the SLT market in developing regions, is expected to increase consumption in Africa ${ }^{4,5}$. Given the detrimental effects of secondhand smoke, it is not surprising that SLT has been promoted as an alternative to reduce harm, illness and death caused by smoking tobacco ${ }^{6-8}$. However, SLT product use has been linked to a number of adverse health outcomes such as oral, pharynx and oesophagus cancers ${ }^{3,9,10}$. In Africa, 6485 deaths and substantial disability-adjusted life years (DALYs) lost from oral, pharynx and 
oesophagus cancers and ischemic heart disease were attributed to SLT use in $2010^{3}$. This underscores the need to promote SLT cessation. Unless timely action is taken, it is unlikely that the world will reach the World Health Organization (WHO) Member States' $30 \%$ global tobacco use reduction target by 2025 .

The WHO Framework Convention on Tobacco Control (FCTC) offers a set of affordable, evidencebased tobacco prevention and control measures. Promoting cessation of tobacco use and providing adequate treatment for tobacco dependence are among the demand-reduction measures recommended by the $\mathrm{FCTC}^{11}$. The minimum policy recommendations for a cessation intervention include: cessation advice in primary health care systems, access to free telephone cessation quitlines, and free or lowcost pharmacological therapy. Literature from highincome countries suggests that cessation interventions have been part of successful cessation and are costeffective ${ }^{12-16}$.

Nevertheless, most African countries, including Ethiopia, have not implemented comprehensive tobacco control policies or practices as suggested by WHO FCTC ${ }^{4,17,18}$. Thus, tobacco use is expected to remain unchanged ${ }^{1}$. In 2014, Ethiopia became a Party to the WHO FCTC and its National Assembly enacted a National Tobacco Control Law ${ }^{19}$. However, there is no comprehensive tobacco cessation intervention for those who seek to quit; the health care system is not oriented in a way to develop and implement tobacco cessation programs ${ }^{20,21}$.

In recent studies conducted in Ethiopia, it was found that $45.3 \%$ of adults were current SLT users ${ }^{22}$, and $35.5 \%$ intended to quit $\mathrm{SLT}^{23}$, whereas only less than one-third of the $45.3 \%$ had reported a cessation attempt ${ }^{22}$. Studies on cessation attempts, conducted in areas where there are already comprehensive cessation interventions, have shown that many SLT users attempt to quit and are willing to quit. Factors such as sociodemographic characteristics ${ }^{24}$, health professional advice ${ }^{24-26}$, knowledge of adverse health consequences $^{26-28}$, and tobacco risk perception ${ }^{29}$ were associated with cessation attempts.

In the current study, we aim to identify the level of cessation and associated predictors among SLT users who live in areas where there is no cessation intervention. This research builds on a recent study, which demonstrated that cessation intervention users differed from non-cessation intervention users in their cessation attempts ${ }^{24}$.

Finally, most existing studies do not consider the status of SLT use. They use an aggregate of daily and occasional users instead of examining predictors for cessation attempts, for each group independently ${ }^{24,27,28,30}$. Studies have shown that there is a difference between daily and occasional tobacco users with regard to motivation ${ }^{31}$, perception $^{32}$, and affect $^{33}$. The objective of this study was to determine cessation attempts and related factors among daily SLT users.

\section{METHODS}

\section{Study settings}

This study used data from the second-phase survey of prevalence and factors that influence SLT use among adults in pastoralist communities in the Borena Zone, Ethiopia ${ }^{22}$. The study was conducted in three districts (Yabello, Arero, and Moyale) in the Borena zone, south Ethiopia. Moyale district is situated along Ethiopia's borders with Somalia and Northern Kenya.

\section{Design and data source}

The data used in this study were derived from a cross-sectional survey conducted 1-20 January 2016 , among adult (aged $\geq 18$ years) SLT users in the Borena zone, Ethiopia. The data were collected from 810 randomly selected SLT users. Our analysis focused on 600 daily users ${ }^{23}$.

\section{Study population and sampling}

A multi-stage sampling procedure was used to identify the sample (current SLT users). In the first stage, three districts were selected randomly from the districts in the zone. In the second stage, 30\% of the kebeles (the smallest administrative units) were selected from each district. The sample size was allocated proportionally based on the number of SLT users identified by census conducted in the selected kebeles. Finally, the study participants were selected through simple random sampling ${ }^{23}$.

\section{Data collection}

The data were collected using a structured and pretested questionnaire. The questionnaire developed in English was translated into the local language (Afan Oromo). A person blind to the English version 
performed a back-translation to English to check for consistency. Trained researchers collected the data. To maintain data quality, the interviewers were trained, the questionnaire was pilot-tested before the actual data collection, and frequent supervision was conducted during the data collection process ${ }^{23}$.

Ethics approval for this study was not required since the data used were secondary. Ethical clearance for a primary survey was obtained from the research ethics committee of Jimma University (Ref: RPGC/200/2015).

\section{Measures}

\section{Outcome variable}

The outcome variable was SLT cessation attempts (defined as making any attempt to quit SLT in the past twelve months). Cessation attempts were counted by asking the respondent whether a quit attempt was made during the 12 months prior to the study. The duration of the most recent cessation was categorized as $\leq$ one month and $>$ one month ${ }^{24}$.

\section{Explanatory variables}

We included a number of demographic factors: age group (18-30, 31-40, 41-50, and $\geq 51$ years), sex, educational status (unable to read/write, able to read/ write, and formal education), occupation (pastoralist, agro-pastoralist, and other), marital status ( single, married, divorced, and widowed) and religion (Wakefata, Islam, and Christianity).

Knowledge of health risks associated with SLT use (oral cancer, heart diseases, tooth decay, gum diseases, stomach cancers, and pharyngeal/esophageal cancer) was assessed by six items (Kuder-Richardson Formula $20, \mathrm{KR}-20=50$, on a scale $0-100)$. The responses to items were summed to create a knowledge scale.

Health risk perception was measured by nine items (Cronbach's a $=0.84$ ) measured on a 5-point Likert scale (e.g. my chances of getting oral cancer by using SLT are rare: $1=$ strongly disagree; $5=$ strongly agree). All nine items were combined into a sum score to create an overall scale for risk perception.

A modified version of Severson SLT Dependence Scale (SSTDS) was used to assess nicotine dependence. The scale consists of nine items (Cronbach's $\alpha=0.81$ ). The total score for the SSTDS calculated as the sum of all items except the first item. The score ranged from 0 to 18 . Higher scores indicate greater dependence.
Unlike other scales, SSTDS was developed to address multiple dimensions of tobacco dependence and predicts both craving and withdrawal ${ }^{34}$.

Descriptive social norms were assessed by four items (Cronbach's a $=0.61$ ) rated on a 5-point Likert scale (e.g. most people in my neighborhood chew or snuff tobacco. 1 = strongly agree; 2 = disagree; $3=$ undecided; $4=$ agree; $5=$ strongly agree). The scale score was created by summing all items with the higher score reflecting higher descriptive norm.

\section{Analysis}

We performed descriptive statistics to summarize the participants' characteristics, SLT related practices, knowledge of health risks, risk perceptions, and norm. We conducted univariable and multivariable logistic regression analyses for the association between cessation attempt and independent variables. Odds ratios (OR) and $95 \%$ confidence intervals (CIs) were calculated for all variables. Variables with $\mathrm{p}<0.25$ in the univariable analysis were included in a multivariable logistic regression model. A $p<0.05$ was considered statistically significant. All statistical analyses were performed with SPSS version 20.0.

\section{RESULTS}

\section{Sociodemographic characteristics of respondents} Of the study participants, $67.2 \%$ were male, $78.8 \%$ were married, and $75 \%$ were of the Wakefata religion. Nearly $40 \%$ of the respondents were in the age group $31-40$ years. The proportion of males $(22.3 \%)$ who reported cessation attempts was double that $(10.7 \%)$ of females (Table 1).

\section{SLT use}

All respondents were current daily SLT users. Onefourth of respondents were dual-users of cigarettes and SLT (24.8\%). Of all respondents, $18.5 \%$ had attempted to quit in the past 12 months. Of these, $52.3 \%$ abstained from using tobacco for a period of one month or more during their recent cessation attempt. Among participants who attempted to quit SLT use, $20.3 \%$ were in the age group $41-50$ years and $22.3 \%$ were male (Table 1 ).

Only 4.8\% (29/600) of respondents agreed that SLT use causes oral cancer. The majority of respondents knew that SLT can cause tooth decay (70.5\%), mouth sores $(43.8 \%)$ and gum disease $(27.7 \%)$. Nevertheless, 
Table 1. Sociodemographic characteristics of respondents, by cessation status, Borena zone, Ethiopia, $2016(\mathrm{~N}=600)$

\begin{tabular}{|c|c|c|c|}
\hline \multirow[t]{2}{*}{ Variables } & \multirow{2}{*}{$\begin{array}{c}\text { Respondents } \\
\text { In ( } \% \text { o) }\end{array}$} & \multicolumn{2}{|c|}{ Cessation attempt } \\
\hline & & $\operatorname{Ves}(\%)$ & Vo $(\%)$ \\
\hline \multicolumn{4}{|l|}{ Age group (years) } \\
\hline $18-30$ & $25(4.2)$ & 16.0 & 84.0 \\
\hline $31-40$ & 237 (39.5) & 19.0 & 81.0 \\
\hline $41-50$ & $222(37.0)$ & 20.3 & 79.7 \\
\hline $51-60$ & 116 (19.3) & 14.7 & 85.3 \\
\hline \multicolumn{4}{|l|}{ Sex } \\
\hline Male & $403(67.2)$ & 22.3 & 77.7 \\
\hline Female & 197 (32.8) & 10.7 & 89.3 \\
\hline \multicolumn{4}{|l|}{ Marital status } \\
\hline Single & $36(6.0)$ & 19.4 & 80.6 \\
\hline Married & 437 (78.8) & 18.0 & 82.0 \\
\hline Divorced & $40(6.7)$ & 25.0 & 75.0 \\
\hline Widowed & $51(8.5)$ & 17.6 & 82.4 \\
\hline \multicolumn{4}{|l|}{ Religion } \\
\hline Wakefata & 452 (75.3) & 18.6 & 81.4 \\
\hline Islam & $116(19.3)$ & 20.7 & 79.3 \\
\hline Christian & $32(5.3)$ & 9.4 & 90.6 \\
\hline \multicolumn{4}{|l|}{ Educational status } \\
\hline Unable to read/write & 431 (71.8) & 16.9 & 83.1 \\
\hline Able to read/write & $109(18.2)$ & 22.9 & 77.1 \\
\hline Formal education & $60(10.0)$ & 21.7 & 78.3 \\
\hline \multicolumn{4}{|l|}{ Occupation } \\
\hline Pastoralist & 438 (73.0) & 21.7 & 78.3 \\
\hline Agro-pastoralist & $123(20.5)$ & 8.9 & 91.1 \\
\hline Other* & $39(6.5)$ & 12.8 & 87.2 \\
\hline
\end{tabular}

*Student, daily laborer, merchant.

few respondents identified that SLT use is associated with heart disease $(16.8 \%)$, stomach cancer $(3.2 \%)$ and pharyngeal or esophageal cancer (1.5\%).

\section{Perception of risk associated with SLT use, dependence and descriptive norm}

The scores of risk perception ranged 11-44 with a mean of 30.26 and standard deviation (SD) of \pm 6.0 . Half of the respondents reported that getting oral cancer is rare, whereas $49.4 \%$ indicated that they could get gum disease from SLT use. The score of Severson's SLT dependence scale ranged from 0 to 18 with a mean 11.1 and \pm 3.9 SD; the mean score of the social descriptive norm was $11.8( \pm 3.3 \mathrm{SD})$.

Table 2 presents participants' characteristics across dependency score grouped mean rank of tied values. Most of female participants $(47.7 \%)$ were in the first percentile group. Forty per cent of dual-users and those who had no intention to quit SLT were in the middle percentile and first percentile, respectively. The highest proportion of SLT users in the age group $\geq 65$ years was in the first percentile (high) dependency (48.32\%). Compared to dual-users, the proportion of SLT users in the first percentile was higher in the exclusive users $(38.1 \%)$, although this difference was not significant.

\section{Factor associated with a cessation attempt}

In the multiple regression analysis, sex, knowledge of health effects, risk perception, smoking and using SLT (dual-use), and advice from health workers about quitting were positively associated with a cessation attempt. Males were 1.9 times more likely to have made a cessation attempt $(\mathrm{AOR}=1.96,95 \%$ CI: $1.13-$ $3.40)$ compared to females. For each unit increase in knowledge on SLT health effects, participants had

Table 2. Participant characteristics according to the mean rank of tied scores for SLT dependency $(\mathrm{N}=600)$

\begin{tabular}{|c|c|c|c|c|c|}
\hline \multirow[t]{2}{*}{ Variables } & \multicolumn{3}{|c|}{ Percentile SLT dependence score } & \multirow[t]{2}{*}{$\chi^{2}$} & \multirow[t]{2}{*}{$p$} \\
\hline & Ist Count $(\%)$ & 2nd Count ( $\%)$ & 3rd Count ( $\%$ ) & & \\
\hline \multicolumn{6}{|l|}{ Sex } \\
\hline Male & $122(30.3)$ & $142(35.2)$ & $139(34.5)$ & 18.370 & $<0.001$ \\
\hline Female & $94(47.7)$ & $58(29.4)$ & $45(22.8)$ & & \\
\hline \multicolumn{6}{|c|}{ Age group (years) } \\
\hline $18-30$ & $9(36.0)$ & $11(44.0)$ & $5(20.0)$ & 18.431 & 0.005 \\
\hline $31-40$ & $72(30.4)$ & $96(40.5)$ & $69(29.1)$ & & \\
\hline $41-50$ & $79(35.6)$ & $65(29.3)$ & $78(35.1)$ & & \\
\hline$\geq 51$ & $56(48.3)$ & $28(24.1)$ & $32(27.6)$ & & \\
\hline
\end{tabular}


Table 2. Continue

\begin{tabular}{|c|c|c|c|c|c|}
\hline \multirow[t]{2}{*}{ Variables } & \multicolumn{3}{|c|}{ Percentile SLT dependence score } & \multirow[t]{2}{*}{$x^{2}$} & \multirow[t]{2}{*}{ p } \\
\hline & Ist Count $(\%)$ & 2nd Count $(\%)$ & 3rd Count $(\%)$ & & \\
\hline \multicolumn{6}{|c|}{ SLT use behavior } \\
\hline Exclusive user & $171(38.1)$ & $142(31.6)$ & $136(30.3)$ & 4.578 & 0.101 \\
\hline Dual users & 43 (28.9) & $58(38.9)$ & $48(32.2)$ & & \\
\hline \multicolumn{6}{|c|}{$\begin{array}{l}\text { Duration of recent cessation } \\
\text { attempt }\end{array}$} \\
\hline$\leq$ one month & $11(20.8)$ & $23(43.4)$ & $19(35.8)$ & 0.377 & 0.828 \\
\hline$>$ one month & $14(24.1)$ & $22(37.9)$ & $22(37.9)$ & & \\
\hline \multicolumn{6}{|c|}{ Intention to quit SLT } \\
\hline Intend to quit & $51(25.6)$ & 75 (37.7) & $73(36.7)$ & 14.107 & 0.001 \\
\hline No intention & $165(41.1)$ & $125(31.2)$ & $111(27.7)$ & & \\
\hline
\end{tabular}

Ranks are in ascending order.

Table 3. Multivariable logistic regression model predicting cessation attempt among daily SLT users in Borena Zone, South Ethiopia $(\mathrm{N}=600)$

\begin{tabular}{|c|c|c|c|c|c|}
\hline & \multirow[t]{2}{*}{ B } & \multirow[t]{2}{*}{$p$} & \multirow[t]{2}{*}{ AOR } & \multicolumn{2}{|c|}{$95 \% \mathrm{CI}$} \\
\hline & & & & Lower & Upper \\
\hline \multicolumn{6}{|l|}{ Age group (years) } \\
\hline $18-30$ & -0.143 & 0.842 & 0.867 & 0.213 & 3.532 \\
\hline $31-40$ & -0.002 & 0.995 & 0.998 & 0.506 & 1.968 \\
\hline $41-50$ & 0.35 & 0.305 & 1.419 & 0.727 & 2.770 \\
\hline \multicolumn{6}{|l|}{ Sex } \\
\hline Male & 0.676 & 0.016 & 1.966 & 1.135 & 3.406 \\
\hline \multicolumn{6}{|l|}{ Occupation of participant } \\
\hline Agro-pastoralist & -0.485 & 0.209 & 0.616 & 0.289 & 1.311 \\
\hline Other & -0.395 & 0.493 & 0.673 & 0.217 & 2.087 \\
\hline \multicolumn{6}{|l|}{ Educational status } \\
\hline Read and write & 0.301 & 0.313 & 1.351 & 0.753 & 2.423 \\
\hline Formal education & 0.371 & 0.313 & 1.449 & 0.705 & 2.980 \\
\hline \multicolumn{6}{|l|}{ Dual-user } \\
\hline Yes & 0.747 & 0.002 & 2.110 & 1.316 & 3.383 \\
\hline \multicolumn{6}{|c|}{ Advised by health workers to quit } \\
\hline Yes & 0.602 & 0.013 & 1.825 & 1.138 & 2.927 \\
\hline SSTDS & 0.067 & 0.066 & 1.069 & 0.996 & 1.148 \\
\hline Descriptive social norm & -0.012 & 0.726 & 0.988 & 0.922 & 1.058 \\
\hline Knowledge of health risks & 0.188 & 0.042 & 1.206 & 1.007 & 1.445 \\
\hline Risk perception & 0.063 & 0.003 & 1.065 & 1.022 & 1.109 \\
\hline
\end{tabular}

Reference groups: age $\geq 51$ years, female, pastoralist, illiterate, do not smoke cigarettes and use SLT simultaneously, received advice from health workers to quit. Maximum $\mathrm{SE}=0.717$, Hosmer-Lemeshaw $\mathrm{p}=0.201$. AOR: adjusted odds ratio. SSTDS: Severson SLT dependence score.

a $20 \%$ higher probability of cessation $(\mathrm{AOR}=1.206$, 95\% CI: 1.007-1.445). Similarly, one unit increase in the risk perception leads to a 1.06-fold increase in cessation attempts $(\mathrm{AOR}=1.065,95 \% \mathrm{CI}: 1.022-$ 1.109). Dual-users had higher odds of attempting to quit compared with those who use only SLT (AOR=2.11, 95\% CI: 1.316-3.383).

In addition, those who received advice from health workers about quitting SLT were 1.8 times more likely to have a cessation attempt ( $\mathrm{AOR}=1.825,95 \%$ CI: 1.138-2.927) (Table 3).

\section{DISCUSSION}

The WHO FCTC recommends promoting cessation of tobacco. Understanding tobacco cessation and related factors help policy-makers design better tobacco control policies and programs. This study assessed predictors of unaided cessation attempts 
among daily SLT users, which to our knowledge has not been previously quantified in the Ethiopian context. We found that dual use, health professionals' advice, health effects awareness, and risk perception predicted cessation attempt.

Prevalence of cessation attempt was comparable to the rate reported by a study conducted in India30 but much lower than what was reported in other studies $^{24,27,28,35-37}$. Low rate of cessation attempt is a matter of concern because it can be explained by the absence of comprehensive cessation interventions ${ }^{21}$. As in previous studies ${ }^{38,39}$, cessation attempts are related to predicting successful quitting. This implies that interventions aiming to prevent and control tobacco should encourage cessation attempts and endeavour to search for contributory factors beyond the individual or household level.

Our analysis showed that being male predicted cessation attempts. This is probably due to males being more aware of tobacco-related health risks. In this study, we conducted further analysis of knowledge by sex to explain this finding. It showed that $68.3 \%$ of males and $53.8 \%$ of females scored above the mean. A previous study also reported that males were more exposed to anti-tobacco messages than females ${ }^{22}$. This finding may indicate that tobacco cessation interventions should give emphasis to women to encourage them to quit.

Our finding is consistent with other studies showing that health professional advice is a key determinant of cessation attempts ${ }^{24-26}$. We found that being advised to quit tobacco by a health professional was associated with increased odds of cessation attempt. This may signify that encouraging health professionals to take advantage of every contact with SLT users, by giving them brief advice, can increase cessation attempts. In areas where other recommended cessation interventions such as pharmacological therapy and cessation advice provided through free telephone helplines are not available, brief advice provided by health professionals is a promising approach to increase cessation rates.

Risk perception is one of the core constructs in health behavior theories ${ }^{40}$; it is an important predictor of health behaviours ${ }^{41}$. In this study, the positive association between risk perception and cessation attempt was in agreement with findings from a previous study conducted among smokers ${ }^{20}$.
This finding has implications for tobacco control or cessation interventions in designing health messages. Framing health messages to focus on risk perception could help to increase users risk perception and subsequently cessation attempt.

In addition, we identified that knowledge of negative health consequences of SLT were associated with a previous cessation attempt. Each unit increment in knowledge led to an increase of $20.6 \%$ in cessation attempt, and this finding confirmed previous studies results, which revealed that knowledge of negative health consequences is an important predictor of cessation attempt ${ }^{26-28}$. These findings underscore the importance of giving emphasis to increasing knowledge of the health effects of SLT among the public. As reported by different studies, properly framed messages could be successful in increasing cessation success ${ }^{42}$.

\section{Strengths and limitations}

This study reported on SLT users living in a region where there is no organized cessation support, but a need for SLT-use cessation. This is the first study in Ethiopia that addressed unaided SLT cessation attempt and related factors among a large homogenous group. However, it is cross-sectional in design and based on self-reported assessment that might lead to social desirability bias when responding to the questionnaire. Another limitation is that participants' response about nicotine dependency was self-reported and not validated by serum nicotine or cotinine concentrations.

\section{CONCLUSIONS}

This study demonstrated that in areas where there is no comprehensive cessation intervention, cessation attempts are in need of support. The study highlights cessation should emphasize factors such as knowledge of the negative consequences of SLT, risk perception and health professional advice found to be predictors of cessation attempts. Comprehensive cessation intervention is needed to improve cessation attempts and success, especially in regional settings.

\section{REFERENCES}

1. World Health Organization. WHO report on the global tobacco epidemic, 2017: monitoring tobacco use and prevention policies. Geneva, Switzerland: World Health Organization, 2017. https://apps.who.int/iris/ 
bitstream/handle/10665/255874/9789241512824-eng. pdf? sequence $=1 \&$ cisAllowed=y. Accessed June 19, 2019 .

2. World Health Organization, United Nations. Status of Tobacco Production and Trade in Africa: Factsheets. Geneva, Switzerland: World Health Organization; 2015. https://apps.who.int/iris/bitstream/ handle/10665/203234/9789241565127_eng. pdf?sequence=1. Accessed June 19, 2019.

3. Siddiqi K, Shah S, Abbas SM, et al. Global burden of disease due to SLTconsumption in adults: analysis of data from 113 countries. BMC Med. 2015;13(1):194. doi:10.1186/s12916-015-0424-2

4. Lee S, Ling PM, Glantz SA. The vector of the tobacco epidemic: tobacco industry practices in low and middleincome countries. Cancer Causes Control. 2012;23(Suppl 1)117-129. doi:10.1007/s10552-012-9914-0

5. Yach D, Pratt A, Glynn TJ, Reddy KS. Research to stop tobacco deaths. Global Health. 2014;10(1):39. doi:10.1186/1744-8603-10-39

6. Mejia AB, Ling PM, Glantz SA. Quantifying the effects of promoting SLTas a harm reduction strategy in the USA. Tob Control. 2010;19(4):297-305. doi:10.1136/tc.2009.031427

7. Peeters S, Gilmore AB. Transnational Tobacco Company interests in SLTin Europe: analysis of internal industry documents and contemporary industry materials. PLoS Med. 2013;10(9):e1001506. doi:10.1371/journal.pmed.1001506

8. Mejia AB, Ling PM. Tobacco industry consumer research on SLTusers and product development. Am J Public Health. 2010;100(1):78-87. doi:10.2105/AJPH.2008.152603

9. Critchley JA, Unal B. Health effects associated with smokeless tobacco: a systematic review. Thorax. 2003;58(5):435-443. doi:10.1136/thorax.58.5.435

10. Khan Z, Tönnies J, Smokeless Tobacco and Oral Cancer in South Asia: A Systematic Review with MetaAnalysis. Journal of Cancer Epidemiology. 2014. doi:10.1155/2014/394696

11. World Health Organization. Who Framework Convention on Tobacco Control. Geneva, Switzerland: World Health Organization; 2005. http://www.who.int/tobacco/ framework/WHO_FCTC_english.pdf. Accessed June 19, 2019.

12. Stead LF, Buitrago D, Preciado N, Sanchez G, HartmannBoyce J, Lancaster T. Physician advice for smoking cessation. Cochrane Database Syst Rev. 2013;(5):CD000165. doi:10.1002/14651858.CD000165.pub4

13. Cahill K, Stevens S, Perera R, Lancaster T. Pharmacological interventions for smoking cessation: an overview of reviews. Cochrane Database Syst Rev. 2013;(5):CD009329. doi:10.1002/14651858.CD009329.pub2

14. Solberg LI, Maciosek MV, Edwards NM, Khanchandani HS, Goodman MJ. Repeated tobacco-use screening and intervention in clinical practice: health impact and cost effectiveness. Am J Prev Med. 2006;31(1):62-71. doi:10.1016/j.amepre.2006.03.013
15. Maciosek MV, Coffield AB, Edwards NM, Flottemesch TJ, Goodman MJ, Solberg LI. Priorities among effective clinical preventive services: results of a systematic review and analysis. Am J Prev Med. 2006;31(1):52-61. doi:10.1016/j.amepre.2006.03.012

16. West R, Raw M, McNeill A, et al. Health-care interventions to promote and assist tobacco cessation: a review of efficacy, effectiveness and affordability for use in national guideline development. Addiction. 2015;110(9):13881403. doi:10.1111/add.12998

17. Husain MJ, English LM, Ramanandraibe N. An overview of tobacco control and prevention policy status in Africa. Prev Med. 2016;91:S16-22. doi:10.1016/j.ypmed.2016.02.017

18. Tumwine J. Implementation of the framework convention on tobacco control in Africa: current status of legislation. Int J Environ Res Public Health. 2011;8(11):4312-4331. doi:10.3390/ijerph8114312

19. World Health Organization. WHO Africa: Ethiopia's Parliament Champions Tobacco Control. https://www. afro.who.int/news/ethiopias-parliament-championstobacco-control. Accessed July 28, 2018.

20. Abate ZM, Desta TW. Mathiwos Wondu-YeEthiopia Cancer Society (MWECS) experiences in involvement of Ethiopian Tobacco Control Policy Advocacy. Tob Induc Dis. 2018;16(Suppl 1):251-251. doi:10.18332/tid/84179

21. Dereje N. Smoking cessation therapy in Ethiopia: responsiveness and the predictors. Tob Induc Dis. 2018;16(Suppl 1):127-127. doi:10.18332/tid/84110

22. Etu ES, Gemeda DH, Hussen MA. Prevalence and factors that influence smokeless tobacco use among adults in pastoralist communities of Borena Zone, Ethiopia: mixed method study. Tob Induc Dis. 2018;16(Suppl 1):99. doi:10.18332/tid/84104

23. Etu E, Hussen M. Predictors of intention to quit smokeless tobacco among adults in pastoral communities of Borena Zone, South Ethiopia. Tob Induc Dis. 2018;16(Suppl 1):127. doi:10.18332/tid/84119

24. Srivastava S, Malhotra S, Harries AD, Lal P, Arora M. Correlates of tobacco quit attempts and cessation in the adult population of India: secondary analysis of the Global Adult Tobacco Survey, 2009-10. BMC Public Health. 2013;13(1):263. doi:10.1186/1471-2458-13-263

25. Ebbert JO, Elrashidi MY, Stead LF. Interventions for smokeless tobacco use cessation. Cochrane Database Syst Rev. 2015;(10):CD004306. doi:10.1002/14651858.CD004306.pub5

26. Kakde S, Bhopal RS, Jones CM. A systematic review on the social context of smokeless tobacco use in the South Asian population: implications for public health. Public Health. 2012;126(8):635-645. doi:10.1016/j.puhe.2012.05.002

27. Naik BN, Kar SS, Majella MG, Parthibane S. Does awareness on health hazards of tobacco use promote quit attempt? An observational study from urban Pondicherry. Int J Community Med Public Health. 2017;4(5):1787- 
1788. doi:10.18203/2394-6040.ijcmph20171803

28. Hossain MS, Kypri K, Rahman B, Akter S, Milton AH. Health knowledge and smokeless tobacco quit attempts and intentions among married women in rural Bangladesh: Cross-sectional survey. Drug Alcohol Rev. 2016;35(5):514-522. doi:10.1111/dar.12346

29. FitzGerald JM, Poureslami I, Shum J. Assessing beliefs and risk perceptions on smoking and smoking cessation in immigrant Chinese adult smokers residing in Vancouver, Canada: a cross-sectional study. BMJ Open. 2015;5(2):e006435. doi:10.1136/bmjopen-2014-006435

30. Sarkar BK, Arora M, Gupta VK, Reddy KS. Determinants of tobacco cessation behaviour among smokers and SLTusers in the states of Gujarat and Andhra Pradesh, India. Asian Pacific J Cancer Prev. 2013;14(3):19311935. doi:10.7314/apjcp.2013.14.3.1931

31. Haight J, Dickter CL, Forestell CA. A comparison of daily and occasional smokers' implicit affective responses to smoking cues. Addict Behav. 2012;37(3):234-239. doi:10.1016/j.addbeh.2011.10.006

32. McKee G, Barry J, Mullin M, Allwright S, Hayes C. Predictors of Daily and Occasional Smoking and Quitting in Irish University Students. Health. 2017;9(03):435450. doi:10.4236/health.2017.93031

33. Dvorak RD, Simons JS. Affective differences among daily tobacco users, occasional users, and non-users. Addict Behav. 2008;33(1):211-216. doi:10.1016/j.addbeh.2007.09.003

34. Ebbert JO, Severson HH, Danaher BG, Schroeder DR, Glover ED. A comparison of three smokeless tobacco dependence measures. Addic Behav. 2012;37(11):12711277. doi:10.1016/j.addbeh.2012.06.011

35. Ali NS, Khuwaja AK, Ali T, Hameed R. Smokeless tobacco use among adult patients who visited family practice clinics in Karachi, Pakistan. J Oral Pathol Med. 2009;38(5):416421. doi:10.1111/j.1600-0714.2009.00754.x

36. Sreeramareddy CT, Kishore PV, Paudel J, MenezesRG. Prevalence and correlates of tobacco use amongst junior collegiates in twin cities of western Nepal: a crosssectional, questionnaire-based survey. BMC Public Health. 2008;8(1):97. doi:10.1186/1471-2458-8-97

37. Ebbert JO, Glover ED, Shinozaki E, Schroeder DR, Dale LC. Predictors of smokeless tobacco abstinence. Am J Health Behav. 2008;32(6):735-740. doi:10.5993/ajhb.32.6.17

38. Abdullah AS, Driezen P, Quah AC, Nargis N, Fong GT. Predictors of smoking cessation behavior among Bangladeshi adults: findings from ITC Bangladesh survey. Tob Induc Dis. 2015 Dec;13(1):23. doi:10.1186/s12971-015-0050-y

39. Dhumal GG, Pednekar MS, Gupta PC, Sansone GC, Quah AC, Bansal-Travers M, Fong GT. Quit history, intentions to quit, and reasons for considering quitting among tobacco users in India: Findings from the Wave 1 TCP India Survey. Indian J Cancer. 2014;51(01):S39-S45. doi:10.4103/0019-509X.147467
40. Rosenstock IM. The health belief model and preventive health behavior. Health Education Monographs. 1974;2(4):354-386. doi:10.1177/109019817400200405

41. Brewer NT, Chapman GB, Gibbons FX, Gerrard M, McCaul KD, Weinstein ND. Meta-analysis of the relationship between risk perception and health behavior: the example of vaccination. Health Psychol. 2007;26(2):136-145. doi:10.1037/0278-6133.26.2.136

42. Toll BA, Rojewski AM, Duncan LR, et al. "Quitting smoking will benefit your health": the evolution of clinician messaging to encourage tobacco cessation. Clinical Cancer Res. 2014;20(2):301-309. doi:10.1158/1078-0432.CCR-13-2261

ACKNOWLEDGEMENTS

The authors thank Nicole Bergen for critically reviewing and copy editing the manuscript.

\section{CONFLICTS OF INTEREST}

The authors have completed and submitted the ICMJE Form for Disclosure of Potential Conflicts of Interest and none was reported.

\section{FUNDING}

There was no source of funding for this research.

\section{AUTHORS' CONTRIBUTIONS}

MAH conceptualized the study and design. Participated in analysis, interpretation of the results, and wrote the discussion and conclusions sections. ESE participated in the conception of the study, data extraction, analysis, and wrote the results section and reviewed a draft of the manuscript. Both authors read and approved the final manuscript.

\section{PROVENANCE AND PEER REVIEW}

Not commissioned; externally peer reviewed. 